\title{
Simulation of boron effects on OISF-ring dynamics for Czochralski silicon growth: a comparative study
}

\author{
L.I. Huang ${ }^{\mathrm{a}}$, P.C. Lee ${ }^{\mathrm{a}}$, C.K. Hsieh ${ }^{\mathrm{b}}$, W.C. Shu ${ }^{\mathrm{b}}$, C.W. Lan ${ }^{\mathrm{a}, *}$ \\ a Department of Chemical Engineering, National Taiwan University, Taipei 10617, Taiwan, ROC \\ ${ }^{\mathrm{b}}$ Sino-American Silicon Product Inc., Science-Based Industrial Park, Hsinchu, Taiwan, ROC
}

\begin{abstract}
The simulation of boron effects on oxidation-induced stacking fault (OISF) ring is carried out for the Czochralski silicon growth. The simulation is based on either the reaction/diffusion model [Sinno et al., App. Phys. Lett. 75 (1999) 1544] or the electronic-shift model [Voronkov and Falster, J. Appl. Phys. 87 (2000) 4126], while the global heat transfer is simulated by using STHAMAS. The calculated critical $V / G$ values with and without boron doping are in good agreement with the reported values for both models; $V$ is the pulling rate and $G$ the thermal gradient on the ring position at the interface. Nevertheless, for a reasonable prediction by the reaction/diffusion model, the equilibrium concentrations of boron/point-defect pairs need to be several orders larger than the predictions by molecular dynamic simulation. A simplified model without considering the boron dimmers $\left(\mathrm{B}_{2}\right)$ and their associated pairs gives a good prediction as well. On the other hand, the electronic-shift model requires only a single parameter to fit the experimental results. For the electronic-shift model, the ratio of the equilibrium vacancy and self-interstitial concentrations is crucial, while the ratio of their formation energies is found insignificant, but this is not true for the reaction/diffusion model. (C) 2004 Elsevier B.V. All rights reserved.
\end{abstract}

PACS: 44.25. +f; 47.27.Te; 81.10.Fq; 02.60.Cb; 02.70.Fj

Keywords: A1. Computer simulation; A1. Defects; A1. Doping; A1. Heat transfer; A2. Czochralski method

\section{Introduction}

The oxidation-induced stacking fault ring (OISF-ring) is a visible boundary roughly separating the vacancy-rich (inside) and the self-interstitial-rich regions (outside) during silicon ingot growth $[1,2]$. The formation of this boundary was found controlled by a single parameter, i.e., the critical $V / G$ value (or $\xi$ ) [3], where $V$ is the pulling rate and $G$ the thermal gradient on the ring position at the growth interface. This value is

\footnotetext{
*Corresponding author. Fax: + 886-223633917.

E-mail address: cwlan@ntu.edu.tw (C.W. Lan).
}

about $0.13 \mathrm{~mm}^{2} / \operatorname{min~K}[3,4]$. Above the critical value, the ring starts to appear and the vacancy related defects form inside the ring at lower temperature. By using a finite-element analysis, Sinno et al. [4] also obtained a $\xi$ value that is in good agreement with experiments for different crystal sizes and hot zones, and a simple equation was further derived through an asymptotic analysis. The fundamental physics of this is quite simple. As pointed out by Voronkov [3], the equilibrium vacancy concentration at the growth interface is larger than the self-interstitial one, while the self-interstitials diffuse faster than the vacancies. Accordingly, the high pulling rate 
favors the formation of vacancy rich region due to the convective effect. The vacancy-rich region often causes D-defects due to the cluster formation of the vacancies and oxide precipitations can be enhanced through the formation of oxygenvacancy pairs $\left(\mathrm{V}_{2} \mathrm{O}\right)$. On the other hand, $\mathrm{A}$ and $\mathrm{B}$ defects are related to the cluster formation of self-interstitials (e.g. [5,6]).

With doping, the point defect dynamics can be affected. Recently, the experiments [7] have shown that boron affects the OISF-ring formation, and the $\xi$ value increases with the boron concentration. Based on the diffusion and diffusion-limited reactions (referred as the reaction/diffusion model), Sinno et al. [8] performed several calculations showing that the ring position as a function of boron concentration can be predicted nicely using the equilibrium concentrations of boron-interstitial pairs $\left(\mathrm{B}_{2} \mathrm{I}\right.$ and $\left.\mathrm{BI}\right)$ as the adjusting parameters. To have a good agreement with experiments, the equilibrium concentrations of $\mathrm{B}_{2} \mathrm{I}$ and $\mathrm{BI}$ used in their calculations were several orders higher than the values predicted by molecular dynamic simulation based on the tight-binding model [9]. They claimed that the dissolution of boron-interstitial pairs to self-interstitials is the cause of the high critical value in the high boron situation. Nevertheless, the variation of the critical value with the boron concentration was not discussed in their report. Based on a different mechanism using an electronic-shift argument, Voronkov and Falster [10] also obtained a good agreement with the experimental data by using a very simplified model. In their model, they believed that the equilibrium concentrations of the interstitials and vacancies are affected by the electronic shift and the electrical neutrality of the charged defects and dopants. According to their analysis, the critical value increases with the acceptor content, while decreases with the donor concentration. It is still not yet clear which mechanism is correct for the defect dynamics. However, the comparison of both models based on the same thermal condition and solved in a rigorous manner using the same physical properties may provide useful information for future quantitative analysis. The sensitivity study of the physical parameters should also be useful to judge the models' credibility and to provide a better understanding of the OISF-ring dynamics.

In this report, we take the hot zone and the growth conditions from an existing pulling process for 4 and 6-in-diameter ingots. The thermal profiles are computed by STHAMAS [11,12] and further compared with the growth experiments. Based on the thermal analysis, we then perform simulation for point-defect dynamics without and with boron doping and predict the OISF ring formation. Both reaction/diffusion and electronic-shift models are considered in the same point-defect conservation equations. The effects of physical parameters are further examined. In the next section, the models and the simulation are described briefly. Section 3 is devoted to results and discussion, followed by conclusions in Section 4.

\section{Defect dynamics models and numerical computation}

The simulation is carried out for a Kayex CG6000 puller for both 4 and 6-in-diameter silicon growth. The hot-zone configuration is shown in Fig. 1, where the thermal distribution is included (6-in). STHAMAS, a design tool developed by Müller's group at Germany, is used for the global thermal modeling; the 4-in diameter ingot was grown in the same hot zone. The effect of melt convection is approximated by using an effective melt thermal conductivity $(110 \mathrm{~W} / \mathrm{mK})$, while the effect of argon flow is neglected. The calculated power consumption $(98 \mathrm{~kW})$ and reference temperature $(1551 \mathrm{~K})$ for 6 -in-diameter silicon at $60 \mathrm{~mm} / \mathrm{h}$ (with a crystal body length of $40 \mathrm{~cm}$ ) are in good agreement with the measured ones. The reference temperature was taken from the inner edge of the side-wall insulation with the same height of the melt level.

The reaction/diffusion model for the point defects and the associated pairs with boron is described by a pseudo-steady mass balance as the following for the species $i$ [8]:

$$
\nabla \cdot\left(-D_{i} \nabla C_{i}\right)+V \frac{\partial C_{i}}{\partial z}+\sum_{j} R_{i j}=0,
$$




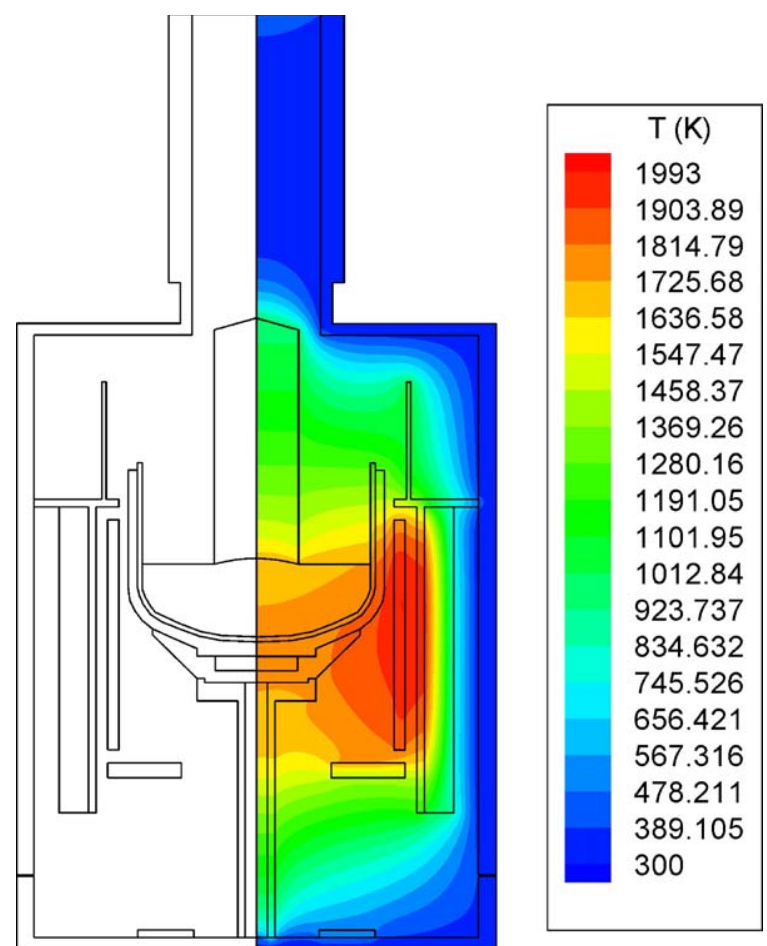

Fig. 1. The schematic of Kayex CG6000 puller and the thermal distribution.

where $\nabla=(\partial / \partial r) \boldsymbol{e}_{\mathrm{r}}+(\partial / \partial z) \boldsymbol{e}_{z}$ for axisymmetry, $D_{i}$ the diffusivity, $C_{i}$ the concentration, $V$ the crystal pulling rate, and $R_{i j}$ the reaction rate with species $j$. Six reactions among seven species are considered:

$\mathrm{I}+\mathrm{V} \rightleftharpoons \mathrm{Si}$

$\mathrm{B}+\mathrm{B} \rightleftharpoons \mathrm{B}_{2}$,

$\mathrm{B}+\mathrm{I} \rightleftharpoons \mathrm{BI}$,

$\mathrm{B}_{2}+\mathrm{I} \rightleftharpoons \mathrm{B}_{2} \mathrm{I}$,

$\mathrm{B}+\mathrm{V} \rightleftharpoons \mathrm{BV}$,

$\mathrm{BI}+\mathrm{V} \rightleftharpoons \mathrm{B}$,

where I stands for the self-interstitials, $\mathrm{V}$ for vacancies, $\mathrm{B}$ for boron, $\mathrm{B}_{2}$ for boron dimmers, $\mathrm{BI}$ for boron/self-interstitial pairs, $\mathrm{B}_{2} \mathrm{I}$ for borondimer/self-interstitial pairs, and BV for the boron/ vacancy pairs. The third equation is often called the kick-out mechanism, while the last equation is the Frank-Turnbull diffusion process. The above reactions are proposed by Sinno et al. [8] based on results of the tight-binding calculations by Luo et al. [9]. The reaction rate $R_{i j}$ can be represented as

$R_{i j}=\psi_{i j} k_{i j}\left(C_{i} C_{j}-C_{i}^{\mathrm{eq}} C_{j}^{\mathrm{eq}} \frac{C_{i j}}{C_{i j}^{\mathrm{eq}}}\right)$,

where $\Psi_{i j}$ is the stoichiometric coefficient (it is +1 or -1 for the species on the left- or right-hand side of the reactions) and

$k_{i j}=\frac{4 \pi a_{\mathrm{r}}}{\Omega C_{\mathrm{s}}}\left(D_{i}+D_{j}\right) \exp \left(\frac{-\Delta G_{i j}}{k_{\mathrm{B}} T}\right)$

is the reaction constant based on diffusion-limited reactions [13]; $a_{\mathrm{r}}$ is the capture radius, $\Omega=1 / 8 a^{3}$, $a$ the lattice constant of silicon, $C_{\mathrm{s}}$ the atomic density, $\Delta G_{i j}$ the reaction energy barrier, $k_{\mathrm{B}}$ the Boltzmann constant, and $T$ the temperature. Also, the formation energy $\left(E_{j}\right)$ and entropy $\left(S_{j}\right)$, as well as the equilibrium concentrations $\left(C_{j}^{\mathrm{eq}}\right)$, of the species $j$, where $j=\mathrm{I}, \mathrm{V}$, etc., are taken from [8], but some values are modified as listed in Table 1; the values reported by Luo et al. [9] and used by Sinno et al. [8] are included for comparison. As will be mentioned shortly, our values have been adjusted to fit the experimental data. In Table 1, the formation entropy (7.63 $k_{\mathrm{B}}$ and $8.2 k_{\mathrm{B}}$ for $\mathrm{B}_{2} \mathrm{I}$ and BI, respectively) used by Sinno et al. [8] gave equilibrium concentrations of $4.24 \times 10^{11}$ and $1.27 \times 10^{13}$, respectively, for $\mathrm{B}_{2} \mathrm{I}$ and $\mathrm{BI}$, which are much lower than the concentrations shown in their result [8, Fig. 2]. Therefore, we have purposely increased the values, as listed in Table 1, for consistence, and the comparison will be given later. In addition, the diffusivity values are the same with the ones used by Sinno et al. [8]. However, the values for $\mathrm{B}_{2}$ and $\mathrm{B}_{2} \mathrm{I}$, which were not mentioned in their paper, are assumed to be two orders smaller than the ones for B and BI, respectively.

The electronic-shift model proposed by Voronkov and Falster [10] is adopted as well, but we have released the assumption of low boron concentration. The newly derived equilibrium vacancy concentration is as the following:

$$
\begin{aligned}
& C_{\mathrm{V}}^{\mathrm{eq}}\left(T, C_{\mathrm{B}}\right) \\
& \quad=\frac{C_{\mathrm{V}}^{\mathrm{eq}}(T)}{n_{0}(T)}\left[\left(\frac{C_{\mathrm{B}}^{2}}{4}+n_{0}^{2}(T)\right)^{1 / 2}-\frac{C_{\mathrm{B}}}{2}\right],
\end{aligned}
$$


Table 1

Selected thermodynamic data for the equilibrium species concentrations; other data are the same as those used in Ref. [8]

\begin{tabular}{|c|c|c|c|c|c|}
\hline \multicolumn{6}{|c|}{$C_{j}^{\mathrm{eq}}=$ Pre-factor $\times \exp \left(S_{j} / k_{\mathrm{B}}\right) \times \exp \left(-E_{j} / k_{\mathrm{B}} T\right) \times C_{\mathrm{B}}\left(\right.$ for $\left.C_{\mathrm{B}}=2.5 \times 10^{18} \mathrm{~cm}^{-3}\right)$} \\
\hline & $j$ & Pre-factor & $E_{j}(\mathrm{eV})$ & $S_{j} / k_{\mathrm{B}}$ & $C_{j}^{\mathrm{eq}}\left(T_{\mathrm{m}}\right)\left(\mathrm{cm}^{-3}\right)$ \\
\hline \multirow[t]{4}{*}{ Luo et al. [9] } & $\mathrm{B}_{2}$ & $3.89 \times 10^{-5}$ & -0.8 & 2.75 & $3.73 \times 10^{17}$ \\
\hline & $\mathrm{B}_{2} \mathrm{I}$ & $7.73 \times 10^{-5}$ & 2.0 & 4.3 & $1.52 \times 10^{10}$ \\
\hline & $\mathrm{BV}$ & 3.69 & 2.3 & 3.3 & $3.38 \times 10^{13}$ \\
\hline & $\mathrm{BI}$ & 2.74 & 3.1 & 1.9 & $2.52 \times 10^{10}$ \\
\hline \multirow[t]{2}{*}{ Sinno et al. [8] } & $\mathrm{B}_{2} \mathrm{I}$ & $7.73 \times 10^{-5}$ & 2.0 & 7.63 & $1.02 \times 10^{12}$ \\
\hline & $\mathrm{BI}$ & 2.74 & 3.1 & 8.2 & $3.3 \times 10^{13}$ \\
\hline \multirow[t]{2}{*}{ This work } & $\mathrm{B}_{2} \mathrm{I}$ & $7.73 \times 10^{-5}$ & 2.0 & 10.8 & $1.01 \times 10^{13}$ \\
\hline & $\mathrm{BI}$ & 2.74 & 3.1 & 10.2 & $1.02 \times 10^{14}$ \\
\hline
\end{tabular}

where $n_{0}$ is the intrinsic carrier concentration; $p n=$ $n_{0}^{2}$, where $p$ and $n$ are the hole and electron concentrations, respectively. Based on the assumption of the prevailing charge state of vacancy being -1 [10], the addition of boron atoms will affect the equilibrium of electrons and holes $\left(p-n=C_{\mathrm{B}}\right)$. Then, Eq. (4) can be easily derived by imposing the charge neutrality condition and the mass action law for $\mathrm{V}^{-}+\mathrm{h}^{+}=\mathrm{V}^{0}$, where $\mathrm{V}^{-}$is the charged vacancy, $\mathrm{h}^{+}$the hole, and $\mathrm{V}^{0}$ the neutral vacancy. By putting this equilibrium concentration (Eq. (4)) into Eq. (1), but considering I and V only (the first reaction in Eq. (2)), we can also compute the point-defect concentration and the position ( $\left.r=R_{\mathrm{OISF}}\right)$ of the OISF-ring, where $C_{\mathrm{I}}=C_{\mathrm{V}}$. Because boron concentration is several-order higher than the equilibrium concentrations of point defects, it is assumed constant everywhere. This gives a self-consistent simulation using the electronic-shift model.

Based on Eq. (4), we can further follow the derivation of Voronkov and Falster [10], with the assumption of the fast recombination rate used in Ref. [3] and can obtain the ratio of the critical $V / G$ value with (denoted by $\xi$ ) and without (denoted by $\xi_{0}$ ) boron as

$$
\begin{aligned}
\frac{\xi}{\xi_{0}}= & \frac{E_{\mathrm{I}} D_{\mathrm{I}}\left(T_{\mathrm{m}}\right) C_{\mathrm{I}}^{\mathrm{eq}}\left(T_{\mathrm{m}}\right)-E_{\mathrm{V}} D_{\mathrm{V}}\left(T_{\mathrm{m}}\right) C_{\mathrm{V}}^{\mathrm{eq}}\left(T_{\mathrm{m}}, C_{\mathrm{B}}\right)}{E_{\mathrm{I}} D_{\mathrm{I}}\left(T_{\mathrm{m}}\right) C_{\mathrm{I}}^{\mathrm{eq}}\left(T_{\mathrm{m}}\right)-E_{\mathrm{V}} D_{\mathrm{V}}\left(T_{\mathrm{m}}\right) C_{\mathrm{V}}^{\mathrm{eq}}\left(T_{\mathrm{m}}\right)} \\
& \times \frac{C_{\mathrm{V}}^{\mathrm{eq}}\left(T_{\mathrm{m}}\right)-C_{\mathrm{I}}^{\mathrm{eq}}\left(T_{\mathrm{m}}\right)}{C_{\mathrm{V}}^{\mathrm{eq}}\left(T_{\mathrm{m}}, C_{\mathrm{B}}\right)-C_{\mathrm{I}}^{\mathrm{eq}}\left(T_{\mathrm{m}}\right)}
\end{aligned}
$$

where $E_{\mathrm{I}}$ and $E_{\mathrm{V}}$ are the formation energy of point defects I and $\mathrm{V}$, respectively. Also, $\xi_{0}$ has been derived by Voronkov [3] as

$\xi_{0}=\frac{E_{\mathrm{V}}+E_{\mathrm{I}}}{2 k T_{\mathrm{m}}^{2}} \frac{D_{\mathrm{I}}\left(T_{\mathrm{m}}\right) C_{\mathrm{I}}^{\mathrm{eq}}\left(T_{\mathrm{m}}\right)-D_{\mathrm{V}}\left(T_{\mathrm{m}}\right) C_{\mathrm{V}}^{\mathrm{eq}}\left(T_{\mathrm{m}}\right)}{C_{\mathrm{V}}^{\mathrm{eq}}\left(T_{\mathrm{m}}\right)-C_{\mathrm{I}}^{\mathrm{eq}}\left(T_{\mathrm{m}}\right)}$.

Because $\quad D_{\mathrm{I}}\left(T_{\mathrm{m}}\right) C_{\mathrm{I}}^{\mathrm{eq}}\left(T_{\mathrm{m}}\right) \quad$ dominates over $D_{\mathrm{V}}\left(T_{\mathrm{m}}\right) C_{\mathrm{V}}^{\mathrm{eq}}\left(T_{\mathrm{m}}\right)$ [3], at low boron concentration, Eq. (5) can be simplified to

$$
\begin{aligned}
\frac{\xi}{\xi_{0}} & =\frac{C_{\mathrm{V}}^{\mathrm{eq}}\left(T_{\mathrm{m}}\right)-C_{\mathrm{I}}^{\mathrm{eq}}\left(T_{\mathrm{m}}\right)}{C_{\mathrm{V}}^{\mathrm{eq}}\left(T_{\mathrm{m}}\right)\left(1-C_{\mathrm{B}} / 2 n_{0}\right)-C_{\mathrm{I}}^{\mathrm{eq}}\left(T_{\mathrm{m}}\right)} \\
& =\frac{1}{1-K C_{\mathrm{B}}},
\end{aligned}
$$

where $K=c /\left[2 n_{0}(c-1)\right]$ and $c=C_{\mathrm{V}}^{\mathrm{eq}} / C_{\mathrm{I}}^{\mathrm{eq}}$. Eq. (7) is the one derived by Voronkov and Falster [10]. Interestingly, as shown in Eqs. (5)-(7), the prediction of $\xi_{0}$ or $\xi / \xi_{0}$ does not need any thermal information in the ingot, and this is due to the fast I-V recombination. One can also see that in Eq. (7), $c$ is the only parameter affecting $\xi / \xi_{0}$. The formation energies of the point defects play no role on this value.

The boundary conditions are straightforward for the above equations. At the interface, the equilibrium species concentrations at the melting temperature are imposed. At the crystal surface, no-flux is assumed; axisymmetry is set at the centerline. With a known thermal distribution calculated by STHAMAS, Eq. (1) for both models 
can then be solved by a finite volume/Newton method [14], where a second-order accuracy approximation is adopted.

\section{Results and discussion}

Without boron doping, we have calculated the thermal gradient by using STHAMAS at the position having $C_{\mathrm{I}}=C_{\mathrm{V}}$ for the growth of 4 and 6-in-diameter silicon ingots, and the results are summarized in Fig. 2. From there, the slope gives the $\xi_{0}$ value of $1.377 \times 10^{-3} \mathrm{~cm}^{2} / \mathrm{min} \mathrm{K}$. This is in good agreement with the one $\left(1.37 \times 10^{-3} \mathrm{~cm}^{2} /\right.$ min K) predicted by Eq. (6) and the one $\left(1.34 \times 10^{-3} \mathrm{~cm}^{2} / \mathrm{min} \mathrm{K}\right)$ by Sinno et al. [4]. Apparently, the detailed thermal distribution in the crystals seems to have little effect on this value. This further confirms the assumption of fast recombination reaction proposed by Voronkov [3].

With boron doping, the calculated axial concentrations of some point defects are shown in Fig. 3. The calculated results by Sinno et al. [8] (also in Table 1) are put together for comparison. The data for the equilibrium concentrations of $\mathrm{B}_{2} \mathrm{I}$ and BI are shown in Table 1. As shown, the values $\left(1.02 \times 10^{12}\right.$ and $3.3 \times 10^{13} / \mathrm{cm}^{3}$ for $\mathrm{B}_{2} \mathrm{I}$ and $\mathrm{BI}$,

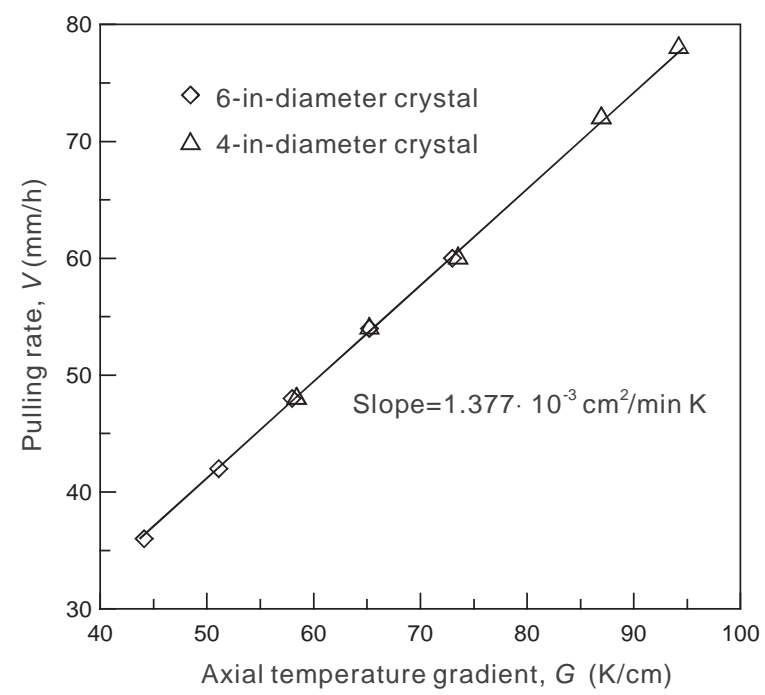

Fig. 2. Puling rate as a function of the axial temperature gradients at the interface (at the ring position) during OISFring formation for both 4 and 6-in-diameter crystals.

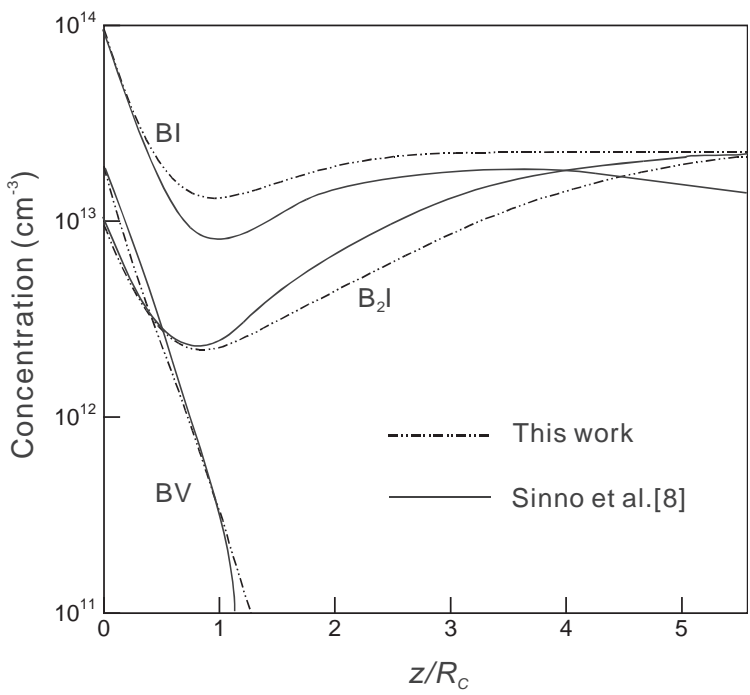

Fig. 3. Axial concentration distribution of $\mathrm{BV}, \mathrm{BI}$, and $\mathrm{B}_{2} \mathrm{I}$ at the position of $0.8 R_{\mathrm{c}} ; R_{\mathrm{c}}$ is the crystal radius. Solid lines are for the results by Sinno et al. [8].

respectively) used by Sinno et al. [8] are not consistent with their calculated concentration at the interface $(z=0)$ shown in Fig. 3. By changing the values of formation entropy for $\mathrm{B}_{2} \mathrm{I}$ and $\mathrm{BI}$, as shown in Table 1, our calculated results can be in good agreement with the ones obtained by Sinno et al. [8], even though the detailed thermal distributions could be quite different. Figs. 4a and $b$ show the comparison of the axial concentration distribution of the point defects at $r=$ $0.8 R_{\mathrm{c}} \quad$ without and with boron doping $\left(C_{\mathrm{B}}=6.7 \times 10^{18} \mathrm{~cm}^{-3}\right)$, respectively; the crystal radius $R_{\mathrm{c}}=3$ in and pulling rate $=60 \mathrm{~mm} / \mathrm{h}$. As shown, without boron doping at this growth condition, both interstitials and vacancies annihilate quickly near the interface $\left(z<0.8 R_{\mathrm{c}}\right)$, and then vacancies dominate in the rest of the ingot. With the boron doping, as illustrated in Fig. 4b, as the fast recombination of interstitials and vacancies proceeds in $z<0.8 R_{\mathrm{c}}, \mathrm{BI}$, and $\mathrm{B}_{2} \mathrm{I}$ start to dissolve according to the le Chetalier's principle to make up the self-interstitials. Although the dissolution of $\mathrm{BV}$ also produces vacancies, its equilibrium concentration is much lower than that of BI. Meanwhile, vacancies continue to be consumed by the Frank-Turnbull mechanism, i.e., the 6th reaction 


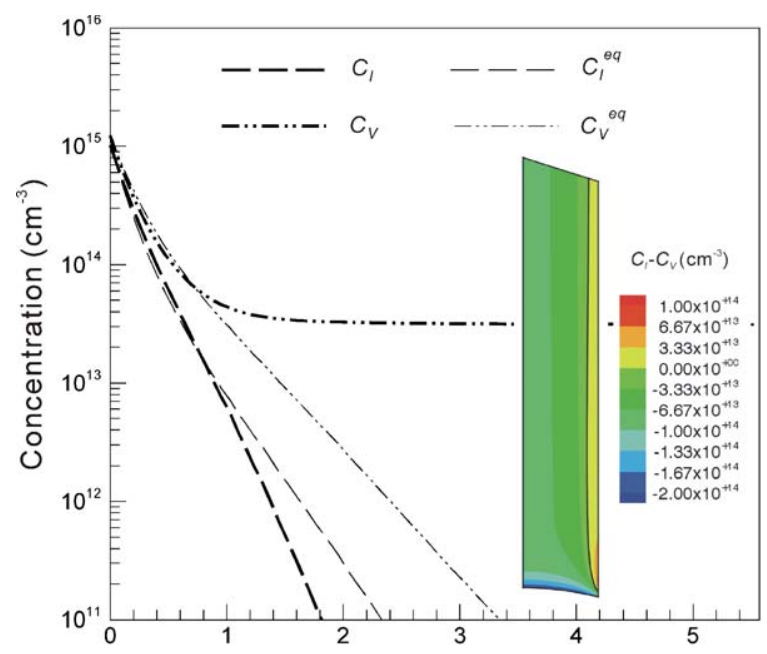

(a)

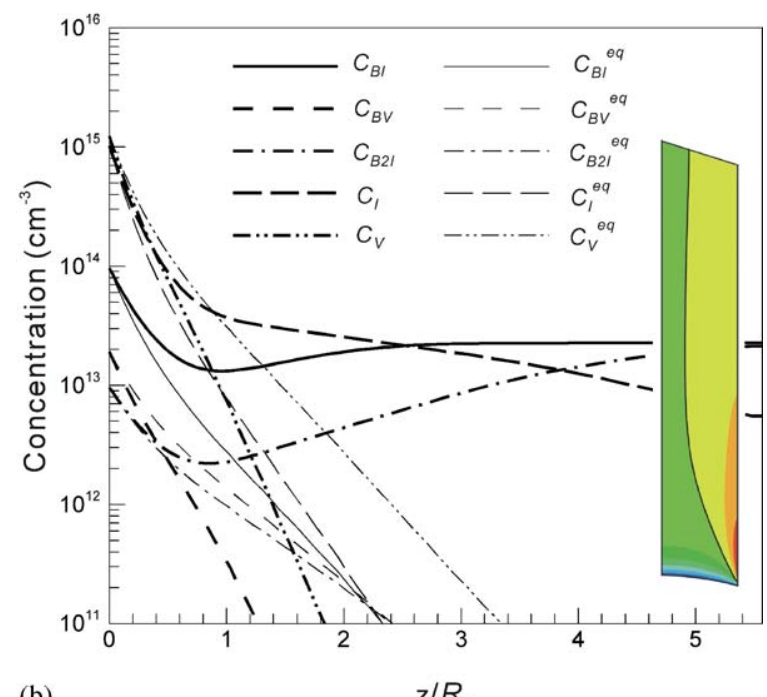

(b)

$z / R_{c}$

Fig. 4. Axial concentration distribution of species at the position of $0.8 R_{\mathrm{c}}$ : (a) without boron; (b) with boron doping $\left(C_{\mathrm{B}}=6.7 \times 10^{18} \mathrm{~cm}^{-3}\right)$. The contours of $C_{\mathrm{I}}-C_{\mathrm{V}}$ in the ingot are also illustrated.

in Eq. (2), and this is significant due to the high concentration of BI. Accordingly, this shifts the point defect balance towards the interstitial-rich region reducing the OISF-ring size. At $z>0.8 R_{\mathrm{c}}$, both $\mathrm{BI}$ and $\mathrm{B}_{2} \mathrm{I}$ start to increase due to the excess interstitials. Since the vacancy concentration is low, the recombination amount is small and the interstitial concentration decreases with the axial distance slowly. Therefore, due to the shift to the interstitial rich region, to keep the same ring size as the one without doping, the corresponding $V / G$ value needs to be increased. For different values of boron concentrations, the calculated $\xi / \xi_{0}$ values are shown in Fig. 5; two pulling rates are considered; different pulling rates give different interface shapes and thermal gradients there. The predicted results by Eq. (5) and the original equation derived by Voronkov and Falster [10], i.e., Eq. (7), with two different $C_{\mathrm{V}}^{\mathrm{eq}} / C_{\mathrm{I}}^{\mathrm{eq}}$ values, i.e., the $c$ value, at the melting point are also illustrated. As shown, the difference between Eqs. (5) and (7) becomes larger at higher boron concentration, but the difference is not much. Again, the results obtained by both models seem to agree with the measured data (the asterisk symbols) quite well.

As shown in Fig. 5, the calculated results based on the electronic-shift model by solving Eqs. (1) and (4) for I and V only with a detailed thermal profile using $c=1.2$ also agree quite well with the prediction by Eq. (5). Similar to the case without doping, this indicates that the fast recombination of the point defects makes the detailed thermal profile in the ingot insignificant. All that matters is

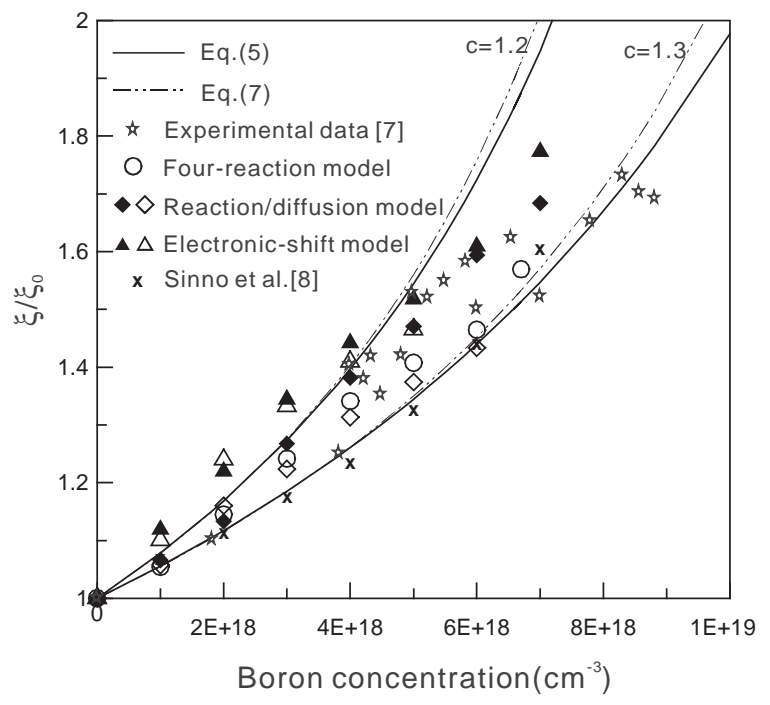

Fig. 5. Comparison of calculated $\xi / \xi_{0}$ values at different boron concentrations using different models; the open symbols are for pulling rate $=60 \mathrm{~mm} / \mathrm{h}$ and the solid symbols for pulling rate $=72 \mathrm{~mm} / \mathrm{h}$. 
Table 2

Effect of $E_{\mathrm{V}} / E_{\mathrm{I}}$ on the calculated OISF-ring size based on the reaction/diffusion and electronic-shift models

\begin{tabular}{|c|c|c|c|c|c|c|c|c|}
\hline \multirow[b]{2}{*}{$a=E_{\mathrm{V}} / E_{\mathrm{I}}$} & \multicolumn{5}{|c|}{ Properties at melting temperature } & \multirow{2}{*}{$\begin{array}{l}C_{\mathrm{B}}=0 \mathrm{~cm}^{-3} \\
R_{\mathrm{OISF}} / R_{\mathrm{c}} \\
\xi_{0}\end{array}$} & \multirow{2}{*}{$\begin{array}{l}\text { Reaction/diffusion model } \\
C_{\mathrm{B}}=6 \times 10^{18} \mathrm{~cm}^{-3} \\
R_{\mathrm{OISF}} / R_{\mathrm{c}} \\
\xi / \xi_{0}\end{array}$} & \multirow{2}{*}{$\begin{array}{l}\text { Electronic-shift model } \\
C_{\mathrm{B}}=6 \times 10^{18} \mathrm{~cm}^{-3} \\
R_{\mathrm{OISF}} / R_{\mathrm{c}} \\
\xi / \xi_{0}\end{array}$} \\
\hline & $E_{\mathrm{V}}(\mathrm{eV})$ & $E_{\mathrm{I}}(\mathrm{eV})$ & $C_{\mathrm{V}}^{\mathrm{eq}}\left(\mathrm{cm}^{-3}\right)$ & $C_{\mathrm{I}}^{\mathrm{eq}}\left(\mathrm{cm}^{-3}\right)$ & $\begin{array}{c}c= \\
C_{\mathrm{V}}^{\text {eq }} / C_{I}^{\text {eq }}\end{array}$ & & & \\
\hline 0.455 & 2.142 & 4.71 & $1.23 \times 10^{15}$ & $1.02 \times 10^{15}$ & 1.2058 & 0.969 & 0.984 & 0.638 \\
\hline 0.72 & 2.87 & 3.98 & $1.23 \times 10^{15}$ & $1.02 \times 10^{15}$ & 1.2058 & $\begin{array}{l}1.377 \\
0.969\end{array}$ & $\begin{array}{l}0.934 \\
0.713\end{array}$ & $\begin{array}{l}1.657 \\
0.598\end{array}$ \\
\hline 1 & 3.425 & 3.425 & $1.23 \times 10^{15}$ & $1.02 \times 10^{15}$ & 1.2058 & $\begin{array}{l}1.377 \\
0.969 \\
1.377\end{array}$ & $\begin{array}{l}1.592 \\
0.969 \\
1\end{array}$ & $\begin{array}{l}1.683 \\
0.608 \\
1.677\end{array}$ \\
\hline
\end{tabular}

the thermal gradient at the place of the OISF-ring, which is incorporated into $\xi / \xi_{0}$ already; the fast decay of interstitials and vacancies is well characterized by the thermal gradient near the interface. The reaction/diffusion model can also give consistent results, but it requires seven partial differential equations and the equilibrium concentrations of the point defects need to be adjusted carefully. Also, the equilibrium concentrations are several orders larger that those predicted by the tight-binding calculations (Table 1). On the other hand, a simplified four-reaction model can be used as well by ignoring $\mathrm{B}_{2}$ and $\mathrm{B}_{2} \mathrm{I}$ due to the low concentration of $\mathrm{B}_{2} \mathrm{I} ; C_{\mathrm{A} 2}$ is almost constant. By adjusting the entropy of formation $\left(S / k_{\mathrm{B}}\right)$ for $\mathrm{BI}$ from 10.2 to 10.555 , the calculated results using this four-reaction model can also have a good agreement with the measured data. Again, the results are shown in Fig. 5.

Finally, the effect of $E_{\mathrm{V}} / E_{\mathrm{I}}$ is considered. Both values vary largely in the literatures. For example, $E_{\mathrm{V}}$ varies from $1.56 \mathrm{eV}$ in Ref. [15] to $4.5 \mathrm{eV}$ in Ref. [3]. Nevertheless, according to the Voronkov model in Eq. (7), the ratio of $E_{\mathrm{V}} / E_{\mathrm{I}}$ is not important. Also, for $\xi_{0}$, as long as $E_{\mathrm{I}}+E_{\mathrm{V}}$ is kept the same, $E_{\mathrm{V}} / E_{\mathrm{I}}$ happens to be insignificant as well. Some calculated results for both models based on different $E_{\mathrm{V}} / E_{\mathrm{I}}$ 's are listed in Table 2 for comparison. As mentioned previously, since the detailed thermal distribution does not affect the result much, the influence of the formation energy should be little. Again, this further validates the
Voronkov's assumption for the electronic-shift model. However, the reaction/diffusion model is found to be sensitive to the $E_{\mathrm{V}} / E_{\mathrm{I}}$ ratio. This may be explained by the concentration profiles shown in Fig. 4b that the relative consumption of the selfinterstitials and vacancies along the growth direction, which are affected by the formation energy, could still be important.

\section{Conclusions and comments}

The simulation of the boron effects on the OISF-ring dynamics has been carried out by using both the reaction/diffusion and electronic-shift models. The calculated results are in good agreements with the reported ones. However, unlike the reaction/diffusion model, the calculated critical $V / G$ values by the electronic-shift model are not affected by the detailed thermal profiles in the ingot. Furthermore, the detailed calculations based on the electronic-shift models agree very well with the simplified asymptotic solution proposed by Voronkov, where the ratio of the equilibrium vacancy and self-interstitial concentrations is the only parameter to the reduced $V / G$ value, i.e., $\xi / \xi_{0}$. On the other hand, the reaction/ diffusion model is more sensitive to the formation energy and requires much more parameters to fit the experimental results. Because $\mathrm{B}_{2} \mathrm{I}$ is not the major species, ignoring $\mathrm{B}_{2} I$ and thus $\mathrm{B}_{2}$ in the reaction mechanisms still gives satisfactory results. 


\section{Acknowledgements}

CWL is grateful for the great hospitality of Prof. R.A. Brown during his visit to MIT in 1997, where this research was initiated. During the stay, the discussion with him and Dr. T. Sinno was fruitful. The software STHAMAS provided by Prof. G. Müller is highly appreciated as well. PCL acknowledges the great hospitality of Prof. Müller's group during her software training in Germany. This study is sponsored by the Ministry of Economics of ROC through the Strategic Technology Development Program.

\section{References}

[1] T. Abe, H. Harada, MRS Symp. Proc. 14 (1983) 18.

[2] R.J. Jaccordine, C.J. Drum, Appl. Phys. Lett. 8 (1966) 29.

[3] V.V. Voronkov, J. Crystal Growth 59 (1982) 625.
[4] T. Sinno, R.A. Brown, W. von Ammon, E. Dornberger, J. Electrochem. Soc. 145 (1998) 302.

[5] R. Falster, V.V. Voronkov, F. Quast, Phys. Stat. Sol. B $222(2000) 219$.

[6] T. Sinno, E. Dornberger, W. von Ammon, R.A. Brown, F. Dupret, Mater. Sci. Eng. 28 (2000) 149.

[7] E. Dornberger, D. Gräf, M. Suhren, U. Lambert, P. Wagner, F. Dupert, W. von Ammon, J. Crystal Growth 180 (1997) 343.

[8] T. Sinno, H. Susanto, R.A. Brown, W. von Ammon, E. Dornberger, Appl. Phys. Lett. 75 (1999) 1544.

[9] W.W. Luo, P.B. Rasband, P. Clancy, J. Appl. Phys. 84 (1998) 2476.

[10] V.V. Voronkov, R. Falster, J. Appl. Phys. 87 (2000) 4126.

[11] E. Dornberger, E. Tomzig, A. Seidl, S. Schmitt, H.J. Leister, Ch. Schmitt, G. Müller, J. Crystal Growth 180 (1997) 461.

[12] J. Fainberg, Ph.D. Thesis, Univ. Erlangen-Nurnberg, 1999.

[13] T.R. Waite, Phys. Rev. 107 (1957) 463.

[14] C.W. Lan, Int. J. Numer. Methods Fluids 19 (1994) 41.

[15] W. Wijaranakla, J. Electrochem. Soc. 140 (1993) 3306. 